\title{
Treatment of Soft Tissue Filler Complications: Expert Consensus Recommendations
}

\author{
Fernando Urdiales-Gálvez ${ }^{1}$ (D) Nuria Escoda Delgado ${ }^{2} \cdot$ Vitor Figueiredo $^{3} \cdot$ \\ José V. Lajo-Plaza ${ }^{4} \cdot$ Mar Mira $^{5}$ • Antonio Moreno ${ }^{6}$ - Francisco Ortíz-Martí ${ }^{7}$. \\ Rosa del Rio-Reyes ${ }^{8}$ - Nazaret Romero-Álvarez ${ }^{9}$ - Sofía Ruiz del Cueto ${ }^{5}$. \\ María A. Segurado ${ }^{10,11} \cdot$ Cristina Villanueva Rebenaque ${ }^{12}$
}

Received: 25 September 2017/ Accepted: 17 December 2017/Published online: 5 January 2018

(C) The Author(s) 2018. This article is an open access publication

\begin{abstract}
Background Dermal fillers have been increasingly used in minimally invasive facial esthetic procedures. This widespread use has led to a rise in reports of associated complications. The aim of this expert consensus report is to describe potential adverse events associated with dermal fillers and to provide guidance on their treatment and avoidance.

Methods A multidisciplinary group of experts in esthetic treatments convened to discuss the management of the complications associated with dermal fillers use. A search was performed for English, French, and Spanish language articles in MEDLINE, the Cochrane Database, and Google Scholar using the search terms "complications" OR "soft filler complications" OR "injectable complications" AND "dermal fillers" AND "Therapy". An initial document was drafted by the Coordinating Committee, and it was
\end{abstract}

Fernando Urdiales-Gálvez

furdiales@institutomedicomiramar.com

1 Instituto Médico Miramar, Paseo de Miramar 21, 29016

Málaga, Spain

2 Centro de Medicina Estética Dra Escoda, Rambla de Catalunya 60, Barcelona, Spain

3 Clínica Milénio, R. Manuel da Silva Leal 11C, Lisbon, Portugal

4 Centro Médico Lajo-Plaza, Calle Moreto 10, Madrid, Spain

5 Clínica Mira + Cueto, Av. de Concha Espina 53, Madrid, Spain

6 Clínica Oftalmológica Antonio Moreno, Calle Esperanto, 19, 29007 Málaga, Spain

7 Teknobell Médicina Estética, Av. Pdte Carrero Blanco 14, Seville, Spain reviewed and modified by the experts, until a final text was agreed upon and validated.

Results The panel addressed consensus recommendations about the classification of filler complications according to the time of onset and about the clinical management of different complications including bruising, swelling, edema, infections, lumps and bumps, skin discoloration, and biofilm formation. Special attention was paid to vascular compromise and retinal artery occlusion.

Conclusions Clinicians should be fully aware of the signs and symptoms related to complications and be prepared to confidently treat them. Establishing action protocols for emergencies, with agents readily available in the office, would reduce the severity of adverse outcomes associated with injection of hyaluronic acid fillers in the cosmetic setting. This document seeks to lay down a set of recommendations and to identify key issues that may be useful
Grupo de Dermatología Pedro Jaén, Calle Cinca 30, Madrid, Spain

9 Clínica de Medicina Estética Dra. Nazaret Romero, Paseo Castellana 123, Madrid, Spain

10 SClinic, Claudio Coello 92, Madrid, Spain

11 Hospital del Sureste Vía Verde, Ronda del Sur 10, Arganda del Rey, Madrid, Spain

12 Clínica de Medicina Estética Dra Villanueva, Carrer de Calvet 10, Barcelona, Spain 
for clinicians who are starting to use dermal fillers. Additionally, this document provides a better understanding about the diagnoses and management of complications if they do occur.

Level of Evidence $V$ This journal requires that authors assign a level of evidence to each article. For a full description of these Evidence-Based Medicine ratings, please refer to the Table of Contents or the online Instructions to Authors www.springer.com/00266.

Keywords Esthetic procedures · Dermal fillers · Complications - Treatment

\section{Introduction}

Dermal fillers have been injected with increasing frequency over the past three decades for soft tissue augmentation by volume expansion in the management of the aging face. Over the past several years, the number of procedures involving soft tissue fillers has increased from 1.6 million per year in 2011 to more than 2.4 million in 2015 [1].

The growing use of dermal fillers, specifically the use of hyaluronic acid (HA), can be explained by their effectiveness and versatility as well as their favorable safety profiles.

Although the incidence of complications is low and the majority of adverse events are mild, the increase in the number of procedures has produced the concurrent increase in the number of complications [2-4]. Among these, serious occurrences are fortunately rare, although probably underreported.

It is noteworthy that proper selection and placement of product can help avoid some complications [5].

The classification of filler complications can be divided according to severity (mild, moderate, or severe); nature (ischemic complications and non-ischemic); or by the time of the onset (early or late) [6, 7]. A classical classification proposed by Rohrich et al. [8] suggested that complications should be classified as early, late, and delayed, roughly defined as less than 14, 14 days to 1 year, and more than 1 year, respectively, as these time frames correlate well with the potential underlying etiology. Although the panel proposes to classify filler complications as immediate onset (up to $24 \mathrm{~h}$ after procedure); early onset ( $24 \mathrm{~h}$ to 4 weeks); and delayed onset (more than 4 weeks), to facilitate the understanding and follow-up of the manuscript, the immediate- and the early-onset complications have been listed together.

Although different papers about the management of dermal filler complications have emerged in the last years [2-4, 6, 7, 9-13], optimal complication management remains an unmet need in the field of esthetic medicine.
This paper aims to describe potential adverse events associated with dermal fillers and to provide guidance on their treatment and avoidance.

\section{Methods}

On November 2016, a multidisciplinary group of experts in esthetic treatments, selected based on their level of expertise in this subject, convened to discuss the management of the complications associated with dermal fillers use. Among the different topics discussed in the meeting, the classification of the filler complications and the management of such complications have emerged as key issues. The authors developed this consensus paper based on those discussions and a review of the current literature.

Searches of MEDLINE (from 2000 to November 2016), the Cochrane Database (from 2000 to November 2016), and Google Scholar were conducted using the search terms "complications" OR "soft filler complications" OR "injectable complications" AND "dermal fillers" AND "Therapy". References cited in selected articles were also reviewed to identify additional relevant reports. Limits were set for articles written in English, French, and Spanish with human subjects. Additional data were identified through bibliographic reviews. Additionally, relevant published national and international guidelines were also scrutinized.

Because of the nature of esthetic procedures, which are usually elective processes, it is not easy to devise meaningful prospective clinical trials that evaluate complications. There are a few prospective trials, but these are often not randomized or controlled. Therefore, our knowledge base mainly comprised case reports and summaries of individual practitioner's experience.

An initial document was drafted by the Coordinating Committee, and it was reviewed by the expert panel members. The Coordinating Committee evaluated the panel's comments and modified the draft as they considered necessary. Subsequent revisions were based on feedback from the other authors until a consensus was achieved, and the final text was then validated (Fig. 1).

The recommendations expounded in this document represent the panel's expert opinion based on their clinical experience as well as on published data regarding dermal filler complications in esthetic procedures.

\section{Results}

According to the time of onset, the panel proposes to classify filler complications as immediate onset (up to $24 \mathrm{~h}$ after procedure); early onset ( $24 \mathrm{~h}$ to 4 weeks); and 
First meeting (November 2016):The panel experts selected an initial list of topics

Systematic literature search

The study coordinators evaluate the selected literature and performed a subsequent critical reading of the selected publications

Study coordinators drafted a document

Second meeting: The panel experts gave their opinion on the content and form of the initial version of the recommendations

Study coordinators evaluated the panel comments and drafted any necessary modifications

Review and validation of the experts

Dissemination and publication of the final document

Fig. 1 Flow diagram of the consensus process

delayed onset (more than 4 weeks). Nevertheless, to make the manuscript reading more pleasant, the immediate- and the early-onset complications have been listed together. The main types of adverse events by time of onset are illustrated in Table 1.

\section{Immediate- and Early-Onset Dermal Filler Complications}

\section{Bruising/Ecchymosis}

Bruising is an understandable and common complication, though unwelcome by patients, of filler injections. Bruising is observed more frequently after injection into the dermal and immediate subdermal planes using fanning and threading techniques [14].

Bruising may be treated with cold compresses after the procedure, arnica, aloe vera, or vitamin $\mathrm{K}$ creams $[6,15,16]$. The risk of bruising may be reduced by injecting the filler slowly. If bruising appears, it can be reduced by pressing with a compress [2].

Different substances associated with anticoagulation including nonsteroidal anti-inflammatory drug medications, many vitamin/herbal supplements, and antiplatelet should be discontinued 7-10 days (not without consultation with the treating physician) prior to treatment to reduce the risk of bruising [2, 16, 17].

Clinical studies evaluating the risk of bleeding in patients undergoing minor dental surgery procedures have reported conflicting results. Several studies reported that the postoperative bleeding rate in patients undergoing oral anticoagulant treatment, such as warfarin or coumadin, was not higher than that in patients not undergoing oral anticoagulant treatment [18-20]. However, some studies have reported more postoperative bleeding in oral anticoagulant treated patients $[21,22]$. The results of a recently published meta-analysis found that although patients treated with oral anticoagulants have a higher postoperative bleeding risk than those not treated with oral anticoagulants following minor dental surgery, local hemostatic methods effectively stopped the bleeding [23].

An expert group consensus report, focused on preventing dermal fillers complications, recommended to reduce the risk of bruising and to pay special attention in patients taking oral anticoagulants [24].

In summary, the risk of bleeding in patients taking oral anticoagulant treatments and with a stable international normalized ratio (INR) in the therapeutic range $2-4$ is really small, and its discontinuation may increase the risk of thrombosis [25].

According to the panel opinion, if the anticoagulant treatment is well balanced, the associated risk of discontinuing the treatment is greater than that of bleeding.

Although it is not forbidden, it is advisable to avoid strenuous exercise for $24 \mathrm{~h}$ to reduce the risk of bruising and swelling [17].

Regarding this issue, the panel recommends:

(a) Prophylaxis: To use arnica with vitamin $\mathrm{K}$ creams for 3 to 4 days.

(b) Treatment: To use arnica and vitamin K creams/ photoprotection.

\section{Swelling and Edema}

Some transient swelling in the immediate postprocedural period is normal and occurs with all dermal fillers, but may vary in timing and severity depending on the specific product used [6, 16]. Besides injection volume and technique, patient factors, such as dermographism, may also influence the amount of swelling. The most commonly affected areas are the lips and the periorbital region. In patients with a long-lasting lip augmentation procedure a transient swelling of the lips may occur.

It should be mentioned that this swelling should not be confused with an antibody-mediated edema (angioedema), which is extremely rare $[19,26]$.

The panel recommends: 
Table 1 Overview of the adverse events associated with the use of dermal fillers. Adapted from Funt and Pavicic [6]

\begin{tabular}{|c|c|c|}
\hline \multirow[t]{2}{*}{ Adverse events } & \multicolumn{2}{|l|}{ Signs and symptoms } \\
\hline & Immediate/early adverse events $^{\mathrm{b}}$ & Delayed adverse events ${ }^{c}$ \\
\hline Injection site reactions $^{\mathrm{a}}$ & $\begin{array}{l}\text { Erythema } \\
\text { Edema } \\
\text { Pain/tenderness } \\
\text { Bruising } \\
\text { Itching }\end{array}$ & $\begin{array}{l}\text { Erythema } \\
\text { Edema } \\
\text { Pain/tenderness } \\
\text { Nodule/abscess } \\
\text { Systemic responses } \\
\text { Biofilm }\end{array}$ \\
\hline Infection & $\begin{array}{l}\text { Erythema } \\
\text { Edema } \\
\text { Pain/tenderness } \\
\text { Acne papule formation } \\
\text { Nodule/abscess } \\
\text { Herpes outbreak }\end{array}$ & $\begin{array}{l}\text { Biofilm } \\
\text { Herpes outbreak } \\
\text { Foreign-body granuloma }^{\mathrm{d}}\end{array}$ \\
\hline Hypersensitivity & $\begin{array}{l}\text { Erythema } \\
\text { Edema } \\
\text { Pain/tenderness } \\
\text { Non-fluctuant nodules }\end{array}$ & Migration of filler material \\
\hline Technical and placement errors & $\begin{array}{l}\text { Bumps/lumps } \\
\text { Asymmetries } \\
\text { Contour irregularities } \\
\text { Compromised muscle function } \\
\text { Dysesthesias, paresthesias, and anesthesia }\end{array}$ & $\begin{array}{l}\text { Immune reactions } \\
\text { Compromised muscle function } \\
\text { Dysesthesias and paresthesias }\end{array}$ \\
\hline Skin discoloration & $\begin{array}{l}\text { Redness } \\
\text { Whiteness } \\
\text { Hyperpigmentation }\end{array}$ & $\begin{array}{l}\text { Persistent discoloration } \\
\text { Persistent scarring }\end{array}$ \\
\hline Vascular compromise $^{\mathrm{e}}$ & $\begin{array}{l}\text { Blurred vision } \\
\text { Loss of vision } \\
\text { Pain } \\
\text { Blanching }\end{array}$ & Tissue necrosis \\
\hline
\end{tabular}

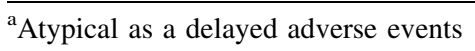

${ }^{\mathrm{b}}$ Occurring up to several days post-treatment

${ }^{\mathrm{c}}$ Occurring from weeks to years post-treatment

${ }^{\mathrm{d}}$ Varying from subclinical histologic changes to disfiguring nodules

${ }^{\mathrm{e}}$ Retinal artery occlusion

(a) Prophylaxis:

i. Anti-inflammatory Enzyme:

1. Wobenzym Vital ${ }^{\circledR}$ (Diafarm, 08210 Barberà del Vallès, Barcelona, Spain): 2 capsules/ $12 \mathrm{~h}$.

2. Bromelain: $300 \mathrm{mg} / \mathrm{day}$, divided in three doses.

ii. Arnica/gelsenium: 4-5 pills/24 h 3-4 days.

iii. Cold compresses (about $5 \mathrm{~min}$ ). (b) Treatment:

i. Mild: Cold compresses/anti-inflammatory enzyme (Wobenzym Vital ${ }^{\circledR}$ or Bromelain, according to the previous dosage)/observation.

ii. Moderate:

1. Streptokinase/streptodornase

$(10,000 / 2500$ $\mathrm{U})$ : 2 pills/8 h, for 3-6 days.

2. Nonsteroidal anti-inflammatory drugs (NSAIDs): 
Table 2 Different NSAIDs and anti-inflammatory enzyme treatments recommended by the panel

\begin{tabular}{lll}
\hline Product & Dose & Comment \\
\hline Diclofenac $50 \mathrm{mg}$ & $1 / 12 \mathrm{~h}$ & Associated with some gastric protector (no more than 5 days) \\
Varidase & $4-8$ pills/6 H and after 2 pills/8 h & For 7-10 days and after for 3-6 days \\
Bromelin $50 \mathrm{mg}^{\mathrm{a}}$ & $4-8 \mathrm{pills} / 24 \mathrm{~h}$ & For 3-6 days \\
$\begin{array}{l}\text { Bromelin, papain, trypsin, and } \\
\quad \text { quimotrypsin }\end{array}$ & $4-8 \mathrm{pills} / 24 \mathrm{~h}$ & For 3-6 days \\
$\begin{array}{l}\text { Ibuprofen } \\
\text { Dexketoprofen trometamol }\end{array}$ & $400-600 \mathrm{mg} / 8 \mathrm{~h}$ & For 2-3 days \\
Acetyl salicylic acid & $25 \mathrm{mg} / 8 \mathrm{~h}$ & For 1-3 days \\
\hline
\end{tabular}

${ }^{a}$ Fortilase $^{\circledR}$, MEDA PHARMA SL, Avenida de Castilla, 2. San Fernando de Henares, Madrid. Spain

${ }^{\mathrm{b}}$ Wowenzym Vital ${ }^{\circledR}$; Diafarma Laboratories, 08210 Barberà del Vallès, Bacrelona. Spain

Table 3 Different steroid treatments recommended by the panel

\begin{tabular}{lll}
\hline Product & Dose & Comment \\
\hline Deflazacort $^{\mathrm{a}}$ & $1-1.5 \mathrm{mg} / \mathrm{kg} /$ day & For 15-21 days. Associated to some gastric protector \\
Prednisone $30 \mathrm{mg}$ & $1 \mathrm{pill} / 24 \mathrm{~h}$ & For 3 days \\
& $30-60 \mathrm{mg} / 24 \mathrm{~h}$ & For 2-3 weeks (corticoids in decreasing doses) \\
Methylprednisolone & $40-80 \mathrm{mg} / 24 \mathrm{~h}$ & For 2-3 weeks (corticoids in decreasing doses) \\
\hline
\end{tabular}

${ }^{a}$ Deflazacort is the first-line treatment. The length of the treatment should be from 3 to 6 weeks, prescribing the drug at increasing doses each week; i.e., first week $0.5 \mathrm{mg} / \mathrm{kg} /$ day until reaching $1.5 \mathrm{mg} / \mathrm{kg} / \mathrm{day}$. Subsequently, corticoids in decreasing doses
- Cox 1: Ibuprofen 400-600 mg/8 h.

- Cox 2: Celecoxib (200-400 mg/24 h).

The different NSAIDs and anti-inflammatory enzyme treatments are summarized in Table 2.

Before prescribing NSAIDs, it is important to consider the following recommendations:

(a) To use the lowest dose and for the shortest time.

(b) To select the NSAID according to the drug profile and the patient risk factors.

(c) To use gastroprotective agents for minimizing the gastrointestinal harm associated with use of NSAIDs.

\section{iii. Severe:}

1. Prednisone: $1 \mathrm{mg} / \mathrm{kg} /$ day + pantoprazole $40 \mathrm{mg}$. Approximately for 3 days (according to the clinical course).

2. Deflazacort: $1-1.5 \mathrm{mg} / \mathrm{kg} /$ day + pantoprazole $40 \mathrm{mg}$. Approximately for 3 days (according to the clinical course).

3. In case of necrosis: lymphatic drainage and soft massage.

The different steroid treatments are summarized in Table 3.
Because dermal fillers are essentially foreign bodies, some patients may develop hypersensitivity to injected products due to an immunoglobulin E (IgE)-mediated immune response (Type I hypersensitivity reaction). Angioedema occurs within hours of exposure, although the reactions can be severe and can last for several weeks [27].

This angioedema will usually subside within a few days with antihistamines and/or oral steroids. The patient should be closely monitored to rule out possible infection.

Additionally, delayed hypersensitivity reactions, which typically occur 1 day after injection, are characterized by induration, erythema, and edema, and are mediated by $\mathrm{T}$ lymphocytes rather than antibodies [28]. Delayed hypersensitivity reactions are non-responsive to antihistamines. In the case of HA, this will involve treatment with hyaluronidase.

\section{Erythema}

Immediately after injection, some skin redness may occur and is normal. Treatments for rosacea may be effective, including oral tetracycline or isotretinoin [6]. A mediumstrength topical steroid is advocated for persistent erythema. However, long-term use of high-potency steroids should be avoided. Additionally, vitamin K cream may be useful in accelerating resolution of erythema [29]. 


\section{Infections}

Any procedure that breaks the surface of the skin carries with it a risk of infection, and injecting dermal fillers is no exception. Acute infections, which appear as acute inflammation or abscesses at the site of injection, are typically due to common pathogens present on the skin such as Staphylococcus aureus or Streptococcus pyogenes.

If untreated, the conditions may lead to sepsis, particularly in elderly people or in patients with other conditions that alter the immune system. Mild forms may be treated with oral antibiotics, while more serious ones require intravenous antibiotics and hospitalization [6, 30].

The panel recommends:

i. Amoxicillin clavulanic acid 4 g/24 h 15 days.

ii. Ciprofloxacin $500-750 \mathrm{mg}$ bid for 2-4 weeks.

The different antibiotics recommended by the panel are listed in Table 4.

\section{Herpetic Outbreak}

Dermal filler injections can lead to reactivation of herpes virus infections. The majority of herpetic recurrences occur in the perioral area, nasal mucosa, and mucosa of the hard palate $[2,6,16,17]$.

Patients with a history of severe cold sores (more than 3 episodes) should be prescribed antiherpes medication prophylactically before treatment when injections in vulnerable areas are planned. In these patients, the panel recommends: Valaciclovir $1 \mathrm{~g} / 24 \mathrm{~h} \quad 1$ day before and 3 days after filler injection.

Additionally, according to the panel recommendations, in patients with active herpes lesions, injections should be delayed until their complete resolution.

\section{Dysesthesias, Paresthesia, and Anesthesia}

Nerve damage during an esthetic procedure, although very rare, can occur as result of different causes such as direct trauma, injection of filler into the nerve, tissue compression

Table 4 Different antibiotic treatments recommended by the panel

\begin{tabular}{lll}
\hline Product & Dose & Comment \\
\hline Amoxycillin/clavulanic acid & $4 \mathrm{~g} / 24 \mathrm{~h}$ & For 10-15 days \\
Cloxacillin & $3 \mathrm{~g} / 24 \mathrm{~h}$ & For 10-15 days \\
& $500 \mathrm{mg} / 8 \mathrm{~h}$ & For 30 days \\
Ciprofloxacin & $500 \mathrm{mg} / 8 \mathrm{~h}$ & For 3-6 weeks \\
Azithromycin & $500 \mathrm{mg} / 24 \mathrm{~h}$ & For 3 days \\
Minocycline & $500 \mathrm{mg} / 12 \mathrm{~h}$ & For 30 days \\
Flucloxacillin & $500 \mathrm{mg} / 8 \mathrm{~h}$ & For 7 days \\
\hline
\end{tabular}

by the product. Nerve injury may be either transient and reversible, or permanent. The most common site of dysesthesias, paresthesia, and anesthesia is the infraorbital nerve. Less commonly, a transient Bell's palsy or marginal mandibular nerve dysfunction has been seen and may last several weeks $[2,6,16,17]$.

Although $71 \%$ of patients with Bell's palsy experience complete spontaneous resolution, the remaining $29 \%$ exhibit lifelong residual hemifacial weakness. Besides the protective strategies of the ocular surface (artificial tears, occlusion, etc.), the mainstay of acute management of Bell's palsy is a short course of high-dose (for example, $1 \mathrm{mg} / \mathrm{kg}$ ) oral steroids [31]. Surgical decompression of the meatal segment, antiviral therapy, electrotherapy, physical therapy, and acupuncture has been proposed, though the evidence does not support their use [31].

The panel considers it crucial to have a thorough knowledge of facial anatomy to minimize the incidence of such complications.

\section{Lumps and Bumps}

Lumps and bumps are one of the most common complications associated with filler injections [16]. They can be classified according their type (non-inflammatory, inflammatory, or infectious) as well as their time to presentation (early, late, or delayed) [8]. As they can arise from a number of causes, investigation may be required to establish a diagnosis. As a general rule, early lumps and bumps present within days or weeks, tend to be painless, and are most likely the result of suboptimal techniques such as excess filler use, superficial placement, and incorrect product for the indication [16, 32]. Lumps occurring in the early post-treatment period may respond to massage.

The panel recommends:

(a) Observation: do not treat if the inflammation is improving.

(b) If the non-inflammatory lump persists, treat the over correction:

i. Needle aspiration or minimal stab wound incision with evacuation.

ii. Hyaluronidase $150 \mathrm{U} / \mathrm{mL}$ (be aware of possible allergic reactions).

iii. To treat the post-inflammatory hyperpigmentation: intense pulsed light/laser; photo-protection; or depigment cream.

Hyaluronidase preparation, dilution, and doses are summarized in Table 5. 
Table 5 Hyaluronidase preparation, dilution, and doses recommended by the panel

\begin{tabular}{ll}
\hline Dilution & Dose \\
\hline $150 \mathrm{IU} / \mathrm{mL}$ saline & $150 \mathrm{IU} / \mathrm{mL}$ \\
$1 \times 10^{4} \mu \mathrm{g}$ in $3 \mathrm{~mL}$ (saline) & $0.3-0.5 \mathrm{~mL}$ per injected point \\
$1 \times 10^{3} \mathrm{IU}$ in $2-4 \mathrm{~mL}$ (saline) & $50-200 \mathrm{IU}$ in nodules \\
$1.5 \times 10^{3} \mathrm{IU}$ in $10 \mathrm{~mL}$ (saline) & $500-1.000 \mathrm{IU}$ in patients at risk of necrosis \\
& $100-200 \mathrm{IU} \mathrm{3-4} \mathrm{mm} \mathrm{in} \mathrm{depth}$ \\
\hline
\end{tabular}

${ }^{a}$ This strategy refers to the injection of hyaluronidase throughout the area around the vascular occlusion point to promote its intravascular penetration and facilitate removal of the HA that is obstructing the vessel
Table 6 Strategies for reducing the risk of skin necrosis with hyaluronic acid fillers

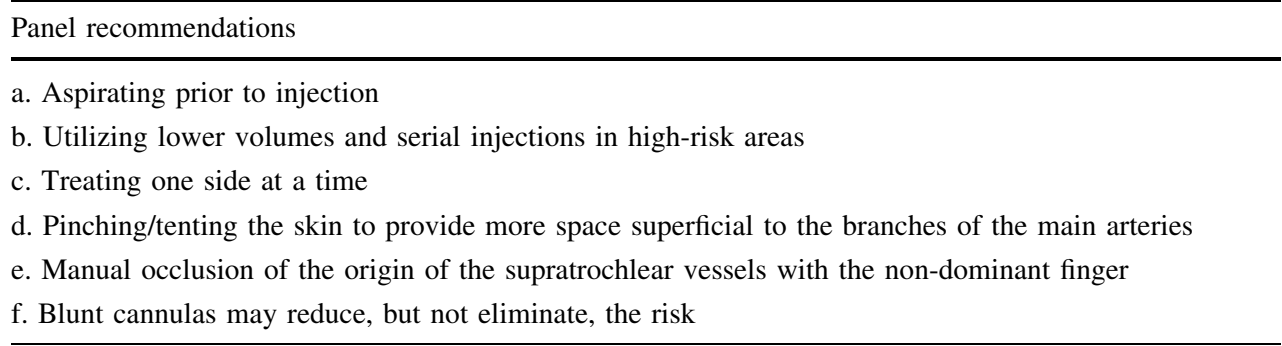

\section{Vascular Compromise}

Vascular compromise after a soft tissue filler injection is a major, immediate complication that is almost always the result of intravascular injection into an artery, causing an embolism that impedes blood flow.

The incidence of intravascular injection seems to be more frequent than we assumed. The results of an internetbased survey conducted on 52 experienced injectors worldwide showed that a $62 \%$ of them reported one or more intravascular injections [32]. Recognition of a vascular event and swift and aggressive treatment is necessary to avoid potentially irreversible complications [33-36].

The two primary diagnostic symptoms of vascular occlusion are pain and changes in skin color. Arterial occlusion is typified by immediate, severe, and disproportionate pain and color changes (white spots) [32], whereas venous occlusion may be associated with less severe, dull, or delayed pain (in some cases there may be no pain).

Because intravascular occlusions are rare events, present recommendations for prevention and management are based almost exclusively on expert opinion [37] and consensus reports [6, 16, 17, 38].

Nevertheless, when vascular occlusion is suspected, it is crucial that the injection is stopped immediately and treatment is rapidly instigated. The objective is to facilitate blood flow to the affected area. Treatment strategies include hyaluronidase, warm compress, massaging or tapping the area, and applying $2 \%$ nitroglycerin paste to promote vasodilatation [32, 39, 40].

Hyaluronidase should be injected immediately, regardless of the filler used, and administered daily in liberal doses where signs and symptoms are present [6, 16, 17, 38].

For intravascular infarction, high doses of hyaluronidase (200-300 U) have been recommended, [16, 17, 38]. When injecting hyaluronidase to treat acute ischemia, consensus recommendations are that the entire ischemic area be treated, not just the site where HA was originally injected $[16,17,38]$. If there is no improvement, the procedure should be repeated hourly until clinical resolution is achieved [16]. Doses up to $1500 \mathrm{U}$ may be required to achieve reversal of vascular compromise [16, 17, 38].

The risk of an intravascular injection can be reduced by different strategies, which are listed in Table 6.

\section{Retinal Artery Occlusion}

The occlusion of the central retinal artery (CRA), or some of its branches, is a rare but devastating visual complication that can occur after an esthetic procedure with soft tissue fillers, such as autologous fat, hyaluronic acid, or collagen [41].

A literature review published in 2015 reported 98 cases of vision changes following filler injection [42]. The injection sites identified with higher risk of complications were the glabella $(38.8 \%)$, nasal region $(25.5 \%)$, nasolabial fold $(13.3 \%)$, and forehead (12.2\%) [42]. As regards, the filler type, autologous fat, was the most common causative material $(47.9 \%)$ followed by hyaluronic acid $(23.5 \%)$ [42].

The underlying mechanism of action leading to vision loss is retrograde flow [42, 43]. If the tip of the needle penetrates the wall of a distal branch of ophthalmic artery, 
the force of injection can expand arterioles and cause retrograde flow [42, 43]. Although this is the prevailing theory regarding the mechanism of occlusion, theories related to compression of vessels may also contribute [43].

The main symptom is blindness in the affected eye, usually painless, which can occur within seconds after injection. Other associated symptoms are pain at the injection site and headache [41-44].

If visual loss has occurred, therapeutic measures should be immediately implemented, because maintained CRA occlusion for more than 60-90 min causes irreversible blindness [45].

The therapeutic measures that have to be performed at the center where the procedure was made would be:

- Medical treatment [43]:

- One drop of topical timolol $0.5 \%$ and/or an acetazolamide $500 \mathrm{mg}$ tablet (after excluding allergy to sulfonamides).

- To administer a sublingual pill $(325 \mathrm{mg}$ ) of acetylsalicylic acid or one of nitroglycerin $0.6 \mathrm{mg}$.

- To administer an intravenous infusion, $100 \mathrm{~mL}$ over 30 min, of mannitol $20 \%$.

- Digital massage [43]: It should start immediately while preparing the treatment and to continue once the drugs have been administered.

- The patient should be placed in a supine position.

- Ensure the patient's eyes are closed.

- Apply firm pressure (enough to ensure that the eyeball is indented about $2-3 \mathrm{~mm}$ ) on the eyeball through the closed eyelids.

- Apply firm pressure for 5-15 s and quickly release.

- Repeat this cycle for at least $5 \mathrm{~min}$.

If despite these measures the patient does not recover the vision in the first $15-20 \mathrm{~min}$, the patient must be referred to an ophthalmology-specialized center for performing an anterior chamber paracentesis for decreasing intraocular pressure [43].

Because, up to now, fibrinolytic or hyaluronidase infiltrations have not demonstrated an unequivocal efficacy; their use is not widespread [43].

Due to the seriousness of the complication, prevention through a good understanding of facial vasculature anatomy and injection techniques is extremely important.

\section{Late-/Delayed-Onset Dermal Filler Complications}

\section{Bruising}

Although bruising is usually an early-onset complication, persisting staining may arise. Larger or cosmetically distressing purpura can be treated with vascular lasers, either pulsed dye light or potassium titanyl phosphate lasers, to speed recovery $[6,16]$.

\section{Edema}

Angioedema Angioedema typically has an early onset; however, episodes that last more than 6 weeks may be observed. These cases are often difficult to treat and have a variable response to medication. The therapeutic approach is stepped, moving to the next step if an inadequate response was obtained. Edema should be controlled with the smallest dose of oral steroids that is effective [6]. Additional treatment options including topical or intralesional steroids, or immunosuppressive agents, have been proposed [2].

Non-Antibody-Mediated (Delayed) Edema Delayed hypersensitivity reactions, which are characterized by induration, erythema, and edema, usually occur 1 day after injection, but may be seen as late as several weeks after injection and may persist for many months [46].

Antihistamines are not effective in these reactions. The best approach is to remove the allergen. If HA had been used, treatment with hyaluronidase would be recommended. Other fillers may require treatment with steroids until the filler resorbs, laser treatment, and/or extrusion [47]. Sometimes, it is even necessary to make, as a last resort, an excision.

Malar Edema Malar edema is a particularly serious complication that has been frequently reported with all fillers when injected into the infraorbital hollow and tear troughs [48].

The phenomenon of malar edema can be explained by an understanding of the anatomy of the lower eyelid. Injection of fillers may cause edema by either augmenting the impermeable barrier of the malar septum (impeding lymphatic drainage) or bydirect pressure on the lymphatics when injection volumes are too large [48].

It is worth mentioning that malar edema is long lasting and responds poorly to treatment. The therapeutic strategies include head elevation, cold compresses, manual compression multiple times daily, lymphatic drainage, and methylprednisolone. In those patients treated with HA, hyaluronidase treatment should be given [48]. 
Nevertheless, the best approach is to reduce its incidence by patient and filler selection; limiting filler volume; and by placing filler material deep into the malar septum at the immediate pre-periosteal level [48].

Persistent periorbital edema can be observed when injecting too much volume in the tear trough or when the product is placed too superiorly and too superficially. This complication is more frequent in patients with preexisting malar edema, because the obstruction of lymphatic drainage may be an inciting factor [16].

\section{Skin Discoloration}

Neovascularization The tissue trauma caused, as a result of tissue expansion and/or by excessive molding and massage of the filler, can favor the appearance of new capillaries, arterioles, and venules. Neovessels may appear days or weeks after the procedure, but should fade within 3-12 months without further treatment. Laser treatment has shown to be effective in these cases.

Hyperpigmentation Hyperpigmentation is not an uncommon complication in dermal filler procedures, especially in subjects with Fitzpatrick skin types IV-VI, although post-injection hyperpigmentation can also be seen in other skin types $[49,50]$.

For managing this problem, the first therapeutic approach should be with a bleaching agent such as topical hydroquinone (2-8\%) and Retin-A (tretinoin) combined with daily full-spectrum sunscreen application [6]. In those cases of resistant post-inflammatory hyperpigmentation, chemical peels may also be used. If the treatment is not successful, the next steps include the treatment with intense pulsed light, a pulsed dye laser, or fractional laser [6].

Tyndall Effect When particulate HA fillers are inappropriately implanted into the superficial dermis or epidermis they cause a bluish hue referred to as "Raleigh scattering" or the "Tyndall effect" [51]. If not treated, superficial product has been commonly observed to last for very long periods of time, even years [16].

Hyaluronidase should be the initial approach to treatment. For those patients who do not achieve a good response, dyspigmentation can be treated by nicking the skin with a small-gauge needle or surgical scalpel and expressing the superficial, unwanted dermal filler [52, 53]. This therapeutic strategy may be applied immediately, or as long as 12 months or more after injection [53].

\section{Infection}

Delayed-onset chronic infections, which generally develop 2 or more weeks after injection, tend to affect a more generalized area and may involve an atypical organism (such as Mycobacteria or Escherichia coli). These are challenging for both diagnosis and treatment and can cause a chronic inflammatory response.

In the opinion of the panel, a sequence of treatment options similar to that in early acute infection should be followed:

(a) To perform a bacterial culture and clinical assessment to decide type of infection and treat with antibiotics or corticosteroids.

(b) It is important to do a differential diagnosis with hypersensitivity, as the use of steroids should be avoided in infection.

(c) There are not comparative studies supporting the effectiveness of a specific therapeutic regimen. Once the species is identified, an antibiogram is required. If atypical mycobacteria are suspected, while waiting for the antibiogram results, an empirical treatment with antibiotics, which cover atypical mycobacteria, such as claritromicina $500 \mathrm{mg} / \mathrm{twice}$ daily combined with ethambutol or rifampicin, may be recommended.

Abscess Abscess formation is a rare complication, reported in permanent hydrogel fillers, occurring any time from 1 week to several years after treatment; it may persist for weeks, and periodically recur for months.

The first-line therapy is drainage and antibiotics. As mentioned for the delayed-onset chronic infections, the panel recommends, in order to tailor the treatment, to obtain bacterial cultures and perform sensitivity reports [54]. Although it is extremely rare, midfacial and periorbital infection may result in intracerebral complications [6].

It has been proposed that low-grade infections are responsible for all delayed-onset complications, including foreign-body granulomas, as a result of biofilm formation [55].

\section{Nodules}

Nodules and lumps are common complications resulting from the use of dermal fillers.

Nodules must be categorized as inflammatory or noninflammatory.

Inflammatory Nodules Delayed-onset nodules (from 4 weeks to 1 year or even longer) are usually inflammatory (immune responses to the filler material) and/or infection related (including biofilm) [56, 57].

Biofilms are widespread in nature and consist of densely packed communities of bacteria that surround themselves with secreted polymers. However, in patients presenting 
delayed inflammatory complications due to permanent filler, biofilm gained much interest after demonstrating that bacteria could be detected in biopsies, although a culture test had frequently been negative [58]. It is therefore important to use molecular techniques, such as polymerase chain reaction or fluorescence in situ hybridization tests for delayed-onset nodule complications where biofilm involvement is suspected [56].

It may be extremely difficult to distinguish inflammation due to a bacterial biofilm from a low-grade hypersensitivity reaction.

Many bacterial species form biofilms, and as biofilms progress, they become more antibiotic and culture resistant. As regards treatment, although these infections are difficult to treat, the cure is removal of the implant, which is not always possible. In those cases of HA fillers, hyaluronidase can be used. However, we must be extremely cautious because, according to the labeling, hyaluronidase should not be used in the presence of an active infection (cellulitis) as it may facilitate the spread of infection into adjacent tissues [37].

Other strategies for treating biofilm include low doses of triamcinolone mixed with 5-fluorouracil (FU) $(0.1 \mathrm{~mL}$ triamcinolone $40 \mathrm{mg} / \mathrm{mL}$ and $0.9 \mathrm{~mL} 5$-FU $50 \mathrm{mg} / \mathrm{mL}$ ) injected at regular (weekly $\times 2$, once every 2 weeks $\times 2$, then monthly) intervals until resolution is achieved [16]. Although the reason for the therapeutic success of 5-FU remains unknown, it has been suggested that it interacts with AriR, a regulatory gene that inhibits the formation of biofilm [59].

Additionally, we have evidence supporting the use of human platelet-rich plasma in the area of the biofilm infection, with a triple effect intention: antimicrobial; for favoring HA degradation of the inflamed tissues; and to destroy the biofilm [60-62].

Regarding antibiotic treatment, a consensus report on prevention and management of HA complications recommended the following empiric antibiotic scheme: clarithromycin $500 \mathrm{mg}$ plus moxifloxacin $400 \mathrm{mg}$ twice daily for 10 days, or ciprofloxacin 500-750 mg twice daily for 2-4 weeks, or minocycline $100 \mathrm{mg}$ once daily for 6 months [17].

Foreign-Body Granulomas Foreign-body granulomas may form as the body's immune system responds to a foreign body that cannot be broken down by the usual mechanisms.

Although they can occur with all injectable dermal fillers, the incidence is very rare (from 0.01 to $1.0 \%$ ) and usually appears after a latent period, which can be several months to years after injection [63, 64]. Diagnosis of granulomas is further complicated by the fact that clinicians are sometimes faced with patients with unknown or incomplete medical and cosmetic treatment history.

Granulomatous reactions to hyaluronic acid fillers can be treated with hyaluronidase with the dosing of $150 \mathrm{U} /$ $\mathrm{mL}$.

Once infection has been ruled out or quiescent, granulomas may respond to oral or intralesional steroids. If steroids are not enough, many patients will respond to the addition of 5-FU to the corticosteroids. In cases of repeated failure of other therapies, surgical excision is the treatment of choice for foreign-body granuloma [2, 6, 16, 17].

\section{Tissue Necrosis}

Impending tissue necrosis, although fortunately rare, may occur as a result of inadvertent injection of filler into vessels supplying the mucosa or the skin, resulting in vessel occlusion. On the other hand, necrosis may also occur secondary to local edema or to occlusion of adjacent vasculature secondary to the hydrophilic properties of the product $[65,66]$.

The risk of skin necrosis can be reduced by different strategies (see Table 6).

All the injectors have to be familiar with the signs of skin necrosis and the appropriate therapy. For intravascular infarction, the panel recommended:

(a) To apply a warm gauze, tapping the area to facilitate vasodilatation, and massage of the area.

(b) To use topical nitroglycerin (1 or $2 \%$ ) paste 2 or 3 times/daily in the office and at home by the patient. Nitroglycerin sublingual tablets can be used.

(c) Hyaluronidase injection (200-400 IU/ 1-2 mL) + massage. See Table 5.

(d) Although it was not absolutely proved, it was stated that acetylsalicylic acid (500 mg/8 h, 24-48 h) might be helpful.

(e) If there are ocular symptoms (blurred vision, loss of vision, or ocular pain), the patient has to be urgently referred to the ophthalmologist.

(f) Other strategies including systemic or topical steroids (prednisone 20-40 mg each day for 3-5 days), low molecular weight heparin, hyperbaric oxygen, sildenafil (1 per day for 3-5 days) have been proposed $[17,67,68]$.

\section{Conclusions}

Because of their efficacy and safety, esthetic procedures with dermal fillers have become increasingly popular. However, although the incidence of complications is relatively low and the majority of adverse events are mild, the 
increase in the number of procedures has been accompanied by a concurrent increase in the number of complications. As optimal complication management remains an unmet need in the field of esthetic medicine, minimizing their incidence by means of appropriate patient, product, and injection technique selection, as well as a sound understanding of facial anatomy, is probably the best approach.

Clinicians should be fully aware of the signs and symptoms related to complications and be prepared to confidently treat them. Establishing action protocols for emergencies, with agents readily available in the office, would reduce the severity of adverse outcomes associated with injection of hyaluronic acid fillers in the cosmetic setting.

It is our hope that this article will help clinicians, who are just starting to use dermal filler procedures, to effectively manage their potential complications.

Acknowledgements The authors wish to thank Allergan Laboratories for their collaboration with the logistics of the meetings and the assistance with the medical writing. The authors thank Antonio Martinez (MD) of Ciencia y Deporte S.L. for providing medical writing and editorial assistance. It should be noted that Allergan S.A. was not involved in the preparation of the recommendations nor did the company influence in any way the scientific consensus reached.

\section{Compliance with Ethical Standards}

Conflict of interest The authors declare that they have no conflicts of interest to disclose.

Open Access This article is distributed under the terms of the Creative Commons Attribution 4.0 International License (http:// creativecommons.org/licenses/by/4.0/), which permits unrestricted use, distribution, and reproduction in any medium, provided you give appropriate credit to the original author(s) and the source, provide a link to the Creative Commons license, and indicate if changes were made.

\section{References}

1. American Society of Plastic Surgeons: 2014 Plastic surgery statistics report. Available at: http://www.plasticsurgery.org/ Documents/news-resources/statistics/2014-statistics/plasticsurgery- statistics-full-report.pdf. Accessed December 26, 2016

2. De Boulle K, Heydenrych I (2015) Patient factors influencing dermal filler complications: prevention, assessment, and treatment. Clin Cosmet Investig Dermatol 8:205-214

3. Ferneini EM, Ferneini AM (2016) An overview of vascular adverse events associated with facial soft tissue fillers: recognition, prevention, and treatment. J Oral Maxillofac Surg 74(8):1630-1636

4. Chiang YZ, Pierone G, Al-Niaimi F (2016) Dermal fillers: pathophysiology, prevention and treatment of complications. J Eur Acad Dermatol Venereol. https://doi.org/10.1111/jdv.13977

5. Sundaram H, Cassuto D (2013) Biophysical characteristics of hyaluronic acid soft-tissue fillers and their relevance to aesthetic applications. Plast Reconstr Surg 132(4 Suppl 2):5S-21S
6. Funt D, Pavicic T (2015) Dermal fillers in aesthetics: an overview of adverse events and treatment approaches. Plast Surg Nurs 35:13-32

7. Wagner RD, Fakhro A, Cox JA, Izaddoost SA (2016) Etiology, prevention, and management of infectious complications of dermal fillers. Semin Plast Surg 30(2):83-86

8. Rohrich RJ, Nguyen AT, Kenkel JM (2009) Lexicon for soft tissue implants. Dermatol Surg 35(Suppl 2):1605-1611

9. Dumitraşcu DI, Georgescu AV (2013) The management of biofilm formation after hyaluronic acid gel filler injections: a review. Clujul Med 86(3):192-195

10. Sorensen EP, Urman C (2015) Cosmetic complications: rare and serious events following botulinum toxin and soft tissue filler administration. J Drugs Dermatol 14(5):486-491

11. Hwang CJ (2016) Periorbital injectables: understanding and avoiding complications. J Cutan Aesthet Surg 9(2):73-79

12. Vanaman M, Fabi SG, Carruthers J (2016) Complications in the Cosmetic dermatology patient: a review and our experience (part 1). Dermatol Surg 42(1):1-11

13. Vanaman M, Fabi SG, Carruthers J (2016) Complications in the cosmetic dermatology patient: a review and our experience (part 2). Dermatol Surg 42(1):12-20

14. Gladstone HB, Cohen JL (2007) Adverse effects when injecting facial fillers. Semin Cutan Med Surg 26(1):34-39

15. Shah NS, Lazarus MC, Bugdodel R et al (2002) The effects of topical vitamin $\mathrm{K}$ on bruising after laser treatment. J Am Acad Dermatol 47(2):241-244

16. Fitzgerald R, Bertucci V, Sykes JM, Duplechain JK (2016) Adverse reactions to injectable fillers. Facial Plast Surg 32(5):532-555

17. Signorini M, Liew S, Sundaram H, De Boulle KL, Goodman GJ, Monheit G et al (2016) Global aesthetics consensus group. Global aesthetics consensus: avoidance and management of complications from hyaluronic acid fillers-evidence- and opinion-based review and consensus recommendations. Plast Reconstr Surg 137(6):961e-971e

18. Bacci C, Maglione M, Favero L, Perini A, Di Lenarda R, Berengo $M$ et al (2010) Management of dental extraction in patients undergoing anticoagulant treatment. Results from a large, multicentre, prospective, case-control study. Thromb Haemost 104(5):972-975

19. Bacci C, Berengo M, Favero L, Zanon E (2011) Safety of dental implant surgery in patients undergoing anticoagulation therapy: a prospective case-control study. Clin Oral Implants Res 22(2):151-156

20. Jimson S, Amaldhas J, Jimson S, Kannan I, Parthiban J (2015) Assessment of bleeding during minor oral surgical procedures and extraction in patients on anticoagulant therapy. J Pharm Bioallied Sci 7(Suppl 1):S134-S137

21. Eichhorn W, Burkert J, Vorwig O, Blessmann M, Cachovan G, Zeuch J et al (2012) Bleeding incidence after oral surgery with continued oral anticoagulation. Clin Oral Investig 16(5):1371-1376

22. Iwabuchi H, Imai Y, Asanami S, Shirakawa M, Yamane GY, Ogiuchi $\mathrm{H}$ et al (2014) Evaluation of postextraction bleeding incidence to compare patients receiving and not receiving warfarin therapy: a cross-sectional, multicentre, observational study. BMJ Open 4(12):e005777

23. Shi Q, Xu J, Zhang T, Zhang B, Liu H (2017) Post-operative bleeding risk in dental surgery for patients on oral anticoagulant therapy: a meta-analysis of observational studies. Front Pharmacol 8:58

24. Urdiales-Gálvez F, Delgado NE, Figueiredo V, Lajo-Plaza JV, Mira M, Ortíz-Martí F et al (2017) Preventing the complications associated with the use of dermal fillers in facial aesthetic procedures: an expert group consensus report. Aesthetic Plast Surg 
25. Perry DJ, Noakes TJ, Helliwell PS, British Dental Society (2007) Guidelines for the management of patients on oral anticoagulants requiring dental surgery. Br Dent J 203(7):389-393

26. Leonhardt JM, Lawrence N, Narins RS (2005) Angioedema acute hypersensitivity reaction to injectable hyaluronic acid. Dermatol Surg 31(5):577-579

27. Van Dyke S, Hays GP, Caglia AE, Caglia M (2010) Severe acute local reactions to a hyaluronic acid-derived dermal filler. J Clin Aesthet Dermatol 3(5):32-35

28. Geisler D, Shumer S, Elson ML (2007) Delayed hypersensitivity reaction to Restylane ${ }^{\circledR}$. Cosmet Dermatol 20(12):784-786

29. Cohen JL, Bhatia AC (2009) The role of topical vitamin K oxide gel in the resolution of postprocedural purpura. J Drugs Dermatol 8(11):1020-1024

30. Christensen LH (2009) Host tissue interaction, fate, and risks of degradable and non-degradable gel fillers. Dermatol Surg 35:1612-1619

31. Glass GE, Tzafetta K (2014) Optimising treatment of Bell's Palsy in primary care: the need for early appropriate referral. Br J Gen Pract 64(629):e807-e809

32. Sclafani AP, Fagien S (2009) Treatment of injectable soft tissue filler complications. Dermatol Surg 35:1672-1680

33. Goodman GJ, Roberts S, Callan P (2016) Experience and management of intravascular injection with facial fillers: results of a multinational survey of experienced injectors. Aesthetic Plast Surg 40(4):549-555

34. Grunebaum LD, Bogdan Allemann I, Dayan S, Mandy S, Baumann L (2009) The risk of alar necrosis associated with dermal filler injection. Dermatol Surg 35(Suppl 2):1635-1640

35. Kwon SG, Hong JW, Roh TS, Kim YS, Rah DK, Kim SS (2013) Ischemic oculomotor nerve palsy and skin necrosis caused by vascular embolization after hyaluronic Acid filler injection: a case report. Ann Plast Surg 71(4):333-334

36. Kim SN, Byun DS, Park JH, Han SW, Baik JS, Kim JY et al (2014) Panophthalmoplegia and vision loss after cosmetic nasal dorsum injection. J Clin Neurosci 21(4):678-680

37. Rzany B, DeLorenzi C (2015) Understanding, avoiding, and managing severe filler complications. Plast Reconstr Surg 136(5 Suppl):196S-203S

38. Cohen JL, Biesman BS, Dayan SH, DeLorenzi C, Lambros VS, Nestor MS et al (2015) Treatment of hyaluronic acid filler-induced impending necrosis with hyaluronidase: consensus recommendations. Aesthet Surg J 35(7):844-849

39. Bailey SH, Cohen JL, Kenkel JM (2011) Etiology, prevention and treatment of dermal filler complications. Aesthetic Surg J $31: 110-121$

40. Kleydman K, Cohen JL, Marmur E (2012) Nitroglycerin: a review of its use in the treatment of vascular occlusion after soft tissue augmentation. Dermatol Surg 38:1889-1897

41. Park SW, Woos SJ, Park KH, Huth JW, Jung C, Kwon OK (2012) Iatrogenic retinal artery occlusion caused by cosmetic facial filler inyections. Am J Ophthalmol 154(4):653-662

42. Beleznay K, Carruthers JD, Humphrey S, Jones D (2015) Avoiding and treating blindness from fillers: a review of the world literature. Dermatol Surg 41(10):1097-1117

43. Loh KT, Chua JJ, Lee HM, Lim JT, Chuah G, Yim B, Puah BK (2016) Prevention and management of vision loss relating to facial filler injections. Singap Med J 57(8):438-443

44. Carruthers JD, Fagien S, Rohrich RJ, Weinkle S, Carruthers A (2014) Blindness caused by cosmetic filler injection: a review of cause and therapy. Plast Reconstr Surg 134(6):1197-1201

45. Hayreh SS, Zimmerman MB (2005) Central retinal artery occlusion: visual outcome. Am J Ophthalmol 140(3):376-391

46. Arron ST, Neuhaus IM (2007) Persistent delayed-type hypersensitivity reaction to injectable non-animal-stabilized hyaluronic acid. J Cosmet Dermatol 6(3):167-171
47. Cassuto D, Marangoni O, De Santis G, Christensen L (2009) Advanced laser techniques for filler-induced complications. Dermatol Surg 35(Suppl 2):1689-1695

48. Funt DK (2011) Avoiding malar edema during midface/cheek augmentation with dermal fillers. J Clin Aesthet Dermatol $4(12): 32-36$

49. Taylor SC, Burgess CM, Callender VD (2009) Safety of nonanimal stabilized hyaluronic acid dermal fillers in patients with skin of color: a randomized, evaluator-blinded comparative trial. Dermatol Surg 35(Suppl 2):1653-1660

50. Heath CR, Taylor SC (2011) Fillers in the skin of color population. J Drugs Dermatol 10(5):494-498

51. DeLorenzi C (2013) Complications of injectable fillers, part I. Aesthet Surg J 33(4):561-575

52. Hirsch RJ, Narurkar V, Carruthers J (2006) Management of injected hyaluronic acid induced Tyndall effects. Lasers Surg Med 38(3):202-204

53. Douse-Dean T, Jacob CI (2008) Fast and easy treatment for reduction of the Tyndall effect secondary to cosmetic use of hyaluronic acid. J Drugs Dermatol 7(3):281-283

54. Rousso JJ, Pitman MJ (2010) Enterococcus faecalis complicating dermal filler injection: a case of virulent facial abscesses. Dermatol Surg 36(10):1638-1641

55. Christensen LH (2009) Host tissue interaction, fate, and risks of degradable and nondegradable gel fillers. Dermatol Surg 35(Suppl 2):1612-1619

56. Dayan SH, Arkins JP, Brindise R (2011) Soft tissue fillers and biofilm. Facial Plast Surg 27:23-28

57. Ledon JA, Savas JA, Yang S, Franca K, Camacho I, Nouri K (2013) Inflammatory nodules following soft tissue filler use: a review of causative agents, pathology and treatment options. Am J Clin Dermatol 14:401-411

58. Bjarnsholt T, Tolker-Nielsen T, Givskov M, Janssen M, Christensen LH (2009) Detection of bacteria by fluorescence in situ hybridization in culture-negative soft tissue filler lesions. Dermatol Surg 35(Suppl 2):1620-1624

59. Attila C, Ueda A, Wood TK (2009) 5-Fluorouracil reduces biofilm formation in Escherichia coli K-12 through global regulator AriR as an antivirulence compound. Appl Microbiol Biotechnol 82(3):525-533

60. Tohidnezhad M, Varoga D, Wruck CJ, Podschun R, Sachweh BH, Bornemann J et al (2012) Platelets display potent antimicrobial activity and release human beta-defensin 2. Platelets 23(3):217-223

61. Albeiroti S, Ayasoufi K, Hill DR, Shen B, de la Motte CA (2015) Platelet hyaluronidase-2: an enzyme that translocates to the surface upon activation to function in extracellular matrix degradation. Blood 125(9):1460-1469

62. Różalski MI, Micota B, Sadowska B, Paszkiewicz M, Więckowska-Szakiel M, Różalska B (2013) Antimicrobial/anti-biofilm activity of expired blood platelets and their released products. Postepy Hig Med Dosw (Online) 67:321-325

63. Lemperle G, Gauthier-Hazan N, Wolters M, Eisemann-Klein M, Zimmermann U, Duffy DM (2009) Foreign body granulomas after all injectable dermal fillers: part 1. Possible causes. Plast Reconstr Surg 123(6):1842-1863

64. Lemperle G, Gauthier-Hazan N (2009) Foreign body granulomas after all injectable dermal fillers: part 2. Treatment options. Plast Reconstr Surg 123(6):1864-1873

65. Hirsch RJ, Cohen JL, Carruthers JD (2007) Successful management of an unusual presentation of impending necrosis following a hyaluronic acid injection embolus and a proposed algorithm for management with hyaluronidase. Dermatol Surg 33(3):357-360

66. Bachmann F, Erdmann R, Hartmann V, Wiest L, Rzany B (2009) The spectrum of adverse reactions after treatment with injectable fillers in the glabellar region: results from the 
Injectable Filler Safety Study. Dermatol Surg 35(Supp1 2):1629-1634

67. Schanz S (2002) Arterial embolization caused by injection of hyaluronic acid (Restylane). Br J Dermatol 146:928-929
68. Beer K, Downie J, Beer J (2012) A treatment protocol for vascular occlusion from particulate soft tissue augmentation. J Clin Aesthet Dermatol 5(5):44-47 